\title{
Applying a transformative learning framework to volunteer tourism
}

\author{
Alexandra Coghlan ${ }^{\mathrm{a}} \&$ Margaret Gooch ${ }^{\mathrm{b}}$ \\ ${ }^{\text {a }}$ International Centre for Ecotourism Research, Griffith \\ University, Gold Coast, Australia \\ ${ }^{\mathrm{b}}$ Cairns Institute Research Fellow, James Cook University, \\ Townsville, Queensland, Australia, 4810
}

To cite this article: Alexandra Coghlan \& Margaret Gooch (2011): Applying a

transformative learning framework to volunteer tourism. Journal of Sustainable Tourism, $19: 6,713-728$

\section{Introduction}

Over the past 20 years volunteer tourism has had mixed reviews in academic circles. Initially perceived as a form of deep ecotourism (Acott et al., 1998; Lindberg et al., 1996; Weaver, 2001), the literature on volunteer tourism gained momentum in the mid-2000's, presenting the sector as an alternative form of tourism that fosters positive social and environmental outcomes by providing tourists with an opportunity to "put something back" into their host community. More recently, however, the pendulum has swung back to a critical analysis of the benefits of volunteer tourism, questioning the (altruistic?) motivations of volunteer tourism, the benefits provided to the local communities and the increasing commercialization of these ventures.

In this paper we reconceptualise volunteer tourism as a form of transformative learning, in which all participants (including members of the host community) learn and change as a result of their experiences. More specifically, we consider those aspects of volunteer tourism that align with the theory and practice of transformative learning, as well as identifying gaps that may impede the transformative process. We pursue the application of transformative learning theory to volunteer tourism, believing it may assist in delivering the societal benefits ascribed to this form of niche tourism. In a series of subsequent papers we will identify some of the existing stumbling blocks created within the sector itself, and suggest ways to overcome those barriers, as well as discuss the ways in which volunteer tourism-based transformative learning may create the conditions necessary for emancipatory social transformation and engagement in participative, democratic processes. 
Following the example set by Percy (2005) who draws interesting comparisons between the theory of transformative learning and participatory research and extension, we suggest that transformative learning may be used as a guiding principle for volunteer tourism outcomes. The application of such a framework may help clarify some of the issues surrounding the nature and purpose of this form of niche tourism. Further, by reframing volunteer tourism as a setting for transformative learning, the tools and techniques for achieving this transformation may be identified, refined, tested and applied.

The recent criticisms of volunteer tourism may be indicative of its current inability to live up to its promises as a vehicle for making positive contributions to host communities. The application of an alternative conceptual framework to this niche sector may reshape it and develop its potential as a tool for positive social and environmental change. For this to happen, we present a shift away from current criticisms of volunteer tourism, and propose a framework based on transformative learning that may be applied at the level of the individual volunteer tourist, and subsequently at a societal level, and that emphasises a range of benefits that this activity may bring

\section{Volunteering and volunteer tourism}

Although traditionally associated with the welfare sector, volunteers are integral to a wide range of social, scientific and environmental endeavours (Volunteering Australia, 2002). Recently, volunteers have appeared in the tourism sector, where volunteer tourism (VT) has the potential to foster cross-cultural understandings, broadening the horizons of both tourists and hosts (Butler, 1990). The most commonly cited definition of this new type of tourism is given by Wearing (2001, p.1) who describes these tourists as "individuals who, for various reasons, volunteer in an organized way to undertake holidays that might involve aiding or alleviating the material poverty of some groups in society, the restoration of certain environments or research into aspects of society or environment".

Other definitions encompass the holidays that provide the chance to re-evaluate personal values, as well to make a difference in the world and put something back into the natural or social environment (Henderson, 1981; Weiler and Richins, 1995; Ellis, 2003; Wearing, 2004; Galley and Clifton, 2005). Uriely et al. (2003) describe volunteer tourism as an expression of the so-called "other" post-modern tourism, with 
a search for the authentic and the experiential. McGehee (2002) and McGehee and Santos (2005) suggest that participation in volunteer tourism has on-going positive effects, particularly in encouraging support for activism and intentions to engage in post-trip social movement activities.

Although many VT participants obviously benefit from their experiences, it is the contribution to society identified by Hill (2001) that underpins the United Nations' (2001) definition of volunteering as a set of behaviours which are undertaken willingly for no financial remuneration, and which benefit society rather than the individual undertaking the activity. Delivering societal benefits sets voluntarism apart from other non-paid activities. Even though societal benefits may be the goal of the participating organisation, mutual benefits for volunteers and the broader society in which the organisation operates are likely outcomes. For example, many people join voluntary organisations because they believe they are donating their time to a worthwhile cause (Pearce, 1993), however others volunteer because they enjoy the nature of the work (Napier \& Gershenfeld, 1999); because they see it as an effective way of 'getting things done' (Donald, 1997, p.484); or to enhance their career paths (Napier \& Gershenfeld 1999; Donald, 1997). According to Stebbins (2001) and Pearce (1993), volunteers are motivated by a combination of perceived personal rewards including learning and sharing new skills; making friends; resolving personal issues through the social interactions that come from volunteering; and a sense of accomplishment.

In some instances, the primary motivation for undertaking volunteer tourism is driven by personal benefits which overshadow altruistic motivations and contradict the United Nations (2001) definition of 'volunteering'. This is supported by studies such as Gray and Campbell's (2007) study of the volunteer tourists in Costa Rica. In their conclusions, they suggest that previous arguments of decommodified and genuine experiences may be oversimplified, as volunteer (eco)tourists have extremely high expectations for interactions with wildlife, as well as for the aesthetic, cultural and authentic nature of the host culture.

To further this point, Gazley (2001) believes that volunteer tourism organisations "blatantly market the more personal benefits, such as cost-savings and personal growth" (p.5) and Simpson (2004) uses this example from Venture Co. to demonstrate the commodified volunteer tourism experiences that appeal to personal benefit-seeking: 
"does the idea of travel to far off destinations appeal to you? How about the adventure of joining an expedition into the world's greatest mountain ranges? And I expect that you'd like to help a disadvantaged community and acquire new skills while working on an aid project... At the same time you're probably thinking about how your Gap Year will fit into the broader picture, will it be something to impress future employers and how will it look on your CV?" (Venture and Co., 2002, p1, taken from Simpson, 2004, p.684).

In their recent work, Lyons and Wearing (2008a, b) argue that as NGOs begin to develop partnerships with corporate entities, they run the risk of losing sight of their core activity of supporting local communities at all costs and instead become engaged in the process of commodification of alternative forms of tourism, including volunteer tourism. These authors question whether a philosophy and practice of volunteer tourism that extends beyond market priorities can be sustained in the global tourism market-place, pointing out that ecotourism has not been able to resist the global commodification in international tourist markets. They believe that we can already find evidence that the commodification of volunteer tourism is occurring with large tour operators competing for a share of this new market (p.153).

Further, the notion that we may be inappropriately propagating western values is a serious concern as, by virtue of its ethical credentials, volunteer tourism is given access to some of the more vulnerable communities and environments around the world. Issues of commodification, globalisation, neo-colonialism and so forth may yet see a more prominent role with studies of volunteer tourism (Guttentag, 2009; Raymond \& Hall, 2008).

Yet when considering the elements of volunteer tourism, there is clearly a sense that it should differ from the broader tourism industry, which is predominantly focused on a profit ethos. Indeed, Zahra and McIntosh (2007) describe the volunteer tourism experience as 'cathartic'. They define cathartic experiences as encounters or activities that "facilitate positive changes and make a positive difference to an individual's relationship and purpose in life" (p.115). In this sense, a critical approach to the study of volunteer tourism is required that identified the desired outcomes to the host community and to the volunteer tourists, and the current practices and trends within the sector. 
One of these outcomes is arguably the creation of transformative learning experiences. Indeed, the authors found evidence for at least five core elements of transformative learning which may be identified in the literature on volunteer tourism. These include (i) seeking deeper involvement with the social and natural world, (ii) a change in context that facilitates transformative learning opportunities, (iii) disorienting dilemmas, (iv) the emergence of confusing emotions, and (v) selfactualisation as an outcome of volunteer tourism. These five elements will provide the framework for this paper and will be presented in turn, after an introduction to the broader concept of transformative learning, and the ways in which we might find common ground between volunteer tourism and transformative learning.

\section{What is transformative learning?}

The first task that faces a reconceptualisation of the type proposed here, is to define our framework. In this case, the framework is conveyed to us through the field of adult education. Originally proposed by Jack Mezirow $(1991,1997,2000)$ to describe a shift in one's assumptions and world beliefs, the theory of transformative learning continues to evolve through the inclusion of new perspectives on adult learning and development, moving from a rational, cognitive base to the inclusion of affective and spiritual dimensions. For the purpose of this article, we use O'Sullivan's (2002, p.11) definition of transformative learning:

"Transformative learning involves experiencing a deep, structural shift in the basic premises of thought, feelings, and actions. It is a shift of consciousness that dramatically and irreversibly alters our way of being in the world. Such a shift involves our understanding of ourselves and our self-locations; our relationships with other humans and with the natural world; our understanding of relations of power in interlocking structures of class, race and gender; our body awarenesses, our visions of alternative approaches to living; and our sense of possibilities for social justice and peace and personal joy."

Whilst the study of transformative learning has been largely derived and applied in formal education settings (Taylor, 2007), many of the findings may be usefully applied here. For instance, the diagram presented in Figure 1 was developed by 
Sipos et al (2008) for their university students in the UBC Centre for Sustainable Food Systems. At a first glance, readers familiar with the practice of volunteer tourism can identify strongly with the themes laid out in and around the circles of Head (engagement), Heart (enablement) and Hands (enactment). This paper does not directly apply this model to volunteer tourism, however it does serve to illustrate some of the similarities between the more formal learning settings and the informal learning opportunties presented by volunteer tourism projects. With this in mind, the concept of transformative learning may be usefully explored within the context of volunteer tourism.

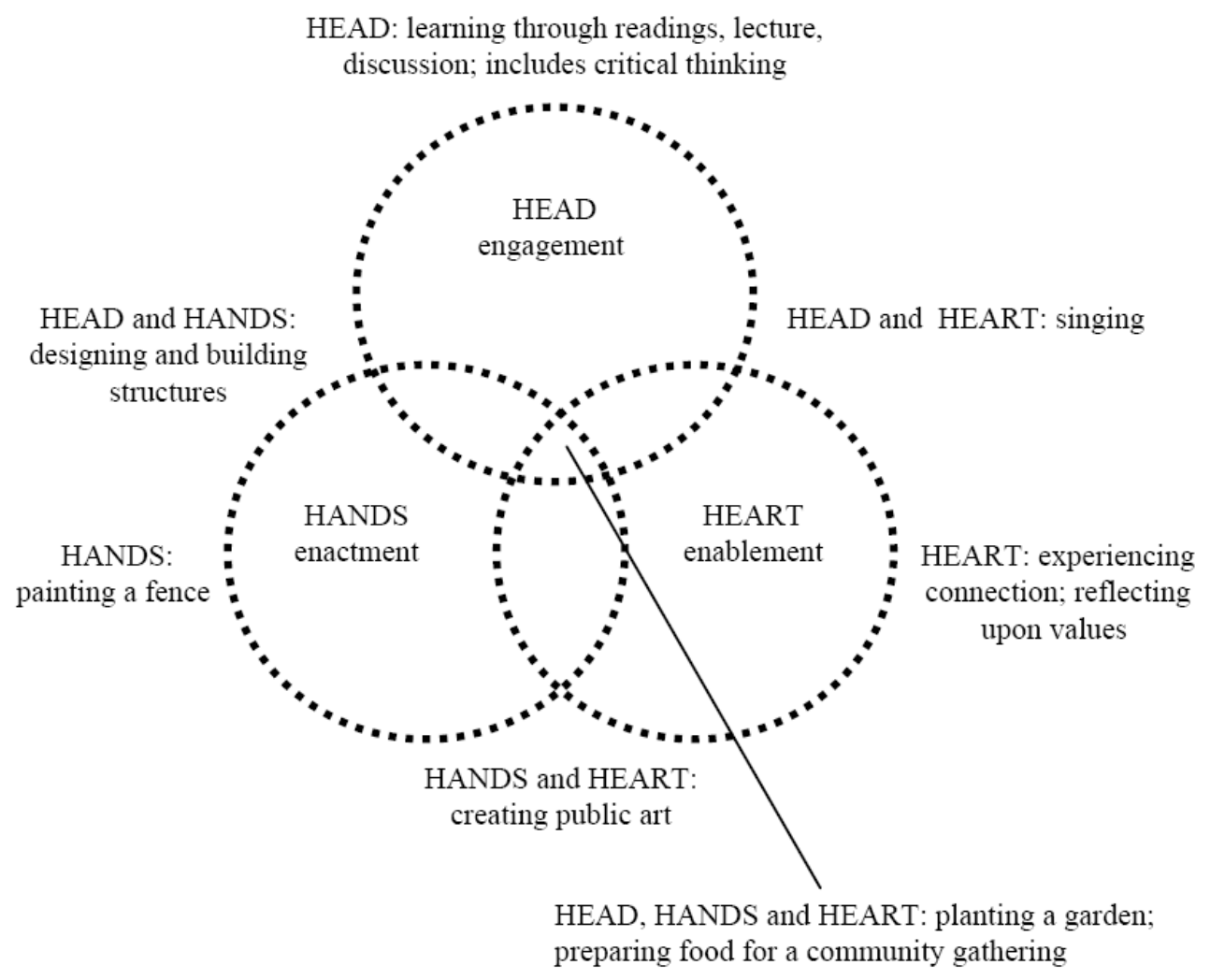

Note: There are seven combinations that can emerge; an example of how each may be actualized is provided

Figure 1. The constituents and synergies leading to transformative sustainability learning taken from Sipos et al. (2008)

\section{How does transformative learning relate to volunteer tourism?}

A number of authors have contributed to the body of knowledge on transformative learning. For readers who seek a deeper treatise of this topic, Mezirow (2003) provides a good overview, whilst Taylor (1998) and O'Sullivan (2001) extend 
Mezirow's material to the affective and spiritual domains. For the purpose of this paper, the authors have sought the common ground around transformative learning and applied it to volunteer tourism. We therefore adopt as central tenants the ideas that transformative learning transforms problematic sets of reference to frames of reference that are more inclusive, discriminating, open, reflective and emotionally able to change (Mezirow, 2003), whereby the individual undergoing change becomes conscious of him or herself as situated within the larger political, economic, sociocultural and spiritual forces. To illustrate this process, Mezirow (1975) proposed 10 phases that led to a transformed state. As we examine the literature on volunteer tourism, we will note the many similarities between the volunteer tourists' experiences and the theory on transformative learning (Table 1). By laying out the similarities and gaps in this way, it becomes apparent that whilst many overlaps exists, there is room for greater alignment and therefore enhanced individual and social outcomes from the volunteer tourism experience.

Table 1: Steps involved in transformative learning and volunteer tourism

\begin{tabular}{|l|l|}
\hline Transformative Learning & Volunteer Tourism \\
\hline & $\begin{array}{l}\text { Step1. Motivation to travel, discover a new } \\
\text { environment, and/or make a contribution } \\
\text { to a social or natural environment. }\end{array}$ \\
\hline $\begin{array}{l}\text { Step 1: Experiencing a disorienting } \\
\text { dilemma }\end{array}$ & $\begin{array}{l}\text { Step 2. Culture shock and experiencing an } \\
\text { unfamiliar cultural/social/natural } \\
\text { environment }\end{array}$ \\
\hline $\begin{array}{l}\text { Step 2: Undergoing self-examination } \\
\text { of internalized role assumptions from } \\
\text { usual social context }\end{array}$ & $\begin{array}{l}\text { Step 3: Opportunities for reflection, } \\
\text { expressed in volunteer diaries as } \\
\text { descriptions of challenging experiences } \\
\text { and emotions }\end{array}$ \\
\hline $\begin{array}{l}\text { Step 4: Relating to other people's } \\
\text { experiences, commonly through dialogue }\end{array}$ & $\begin{array}{l}\text { Step 4: Informal sharing of experiences } \\
\text { during "downtime" such as mealtimes. }\end{array}$ \\
\hline $\begin{array}{l}\text { Step 5: Exploring options for new } \\
\text { behaviours }\end{array}$ & $\begin{array}{l}\text { Step 5: Familiarization with new tasks, } \\
\text { locals habits, etc and opportunities to } \\
\text { contribute knowledge, ideas, and skills. }\end{array}$ \\
\hline $\begin{array}{l}\text { Step 6: Building Competence and self- } \\
\text { confidence in new roles }\end{array}$ & $\begin{array}{l}\text { Limited opportunities in existing volunteer } \\
\text { tourism programs. }\end{array}$ \\
\hline $\begin{array}{l}\text { Step 7: Developing a plan of action } \\
\text { Step 8: Acquisition of knowledge and skills }\end{array}$ & \begin{tabular}{l} 
Step 6: Volunteer self-actualisation, \\
\hline
\end{tabular} \\
\hline
\end{tabular}




\begin{tabular}{|l|l|}
\hline for implementing the plan & $\begin{array}{l}\text { including new values, skills and a sense of } \\
\text { agency }\end{array}$ \\
\hline $\begin{array}{l}\text { Step 9. Provisional efforts to try out new } \\
\text { roles and gain feedback }\end{array}$ & $\begin{array}{l}\text { Limited opportunities in existing volunteer } \\
\text { tourism programs. }\end{array}$ \\
\hline Step 10: Re-integration into society & Step 7: Formation of new social networks \\
\hline
\end{tabular}

1. Disillusion and the search for new frames of reference.

Engagement in transformative learning appears to be driven by an, albeit subconscious, disillusion with existing sets of reference and the search for something new. Lange (2004) refers to the Westerners sense of alienation experienced by those who lack the "larger horizon of meaning beyond the acquisitive self and paid work" (p.135). O'Sullivan (1999) attributes much of this malaise to the forces of globalization, which he describes as "deeply destructive and the end point of a cultural synthesis that is increasingly morbid to the carrying capacities of our planet (p.33). He urges educators to assist learners develop an awareness of our current trajectory, and as part of this (i) to come out of denial, (ii) deal with ensuing despair and (iii) cope with subsequent feeling of loss and grief.

It is not an extensive leap of the imagination to see how volunteer tourism has evolved to fill the gap created by the alienation described by Lange (2004) and O'Sullivan (2001). Volunteer tourists markets are situated predominantly post modern Western societies. A range of authors have characterised such societies as possessing some distinctive characteristics including having reduced levels of spirituality (Morley, 2001; Lash \& Urry, 1994; Urry, 2002). Furthermore, the physical places people live in change rapidly with consequential losses in earlier forms of community identity and a sense of place (Bauman, 1998).

The literature on volunteer tourism suggests that this sector has capitalised on trends such as (i) increased leisure time and volunteering rates, (ii) the rise of alternative forms of tourism, (iii) the popularity of green philosophies and the search for spirituality, (iv) a post-modern demand for new (niche) tourism products, and finally a packaging of experiences that make them accessible to wider markets (Uriely et al., 2003). This trend may be symptomatic of the increasingly commercial nature of volunteer tourism and the growing competition for a demanding and sophisticated market (Cousins et al., 2009). 
2. The importance of context and place: tourism that enables transformative learning.

A key aspect of transformative learning is providing a context for reflection (Taylor, 2007). Brookfield (2000) describes critical transformational learning as the process where people "learn to recognise how uncritically accepted and unjust dominant ideologies are embedded in everyday situations and practices" (p.36). One way to promote a critical reflexion is to step outside of everyday situations and practices. Taylor (2007) mentions the impediments of the learner's socio-cultural context and the dominant ideologies, whilst Davis-Manigaulte, Yorks and Kasl (2006) identify characteristics of a whole-person learning environment that promote transformative learning. These characteristics build on the pedagogy of experiential learning, that builds in opportunities for "felt experiences and unconscious knowing" by drawing in the affective domain, expressed representations of new insights (e.g. through narratives and shared stories) and creating a lived experience of what the learner seeks to understand (p.32).

O'Sullivan (1999) encourages us to think of an education for community and a sense of place. The need for sense of community is notably absent from our culture; instead we cultivate a sense of displacement through heightened mobility patterns and homogenised developments. To overcome a sense of displacement, O'Sullivan encourages educators to foster a sense of place by focussing on bioregions; this would encompass the study of the land as well the history of the communities and peoples that have occupied the region. Again, volunteer tourism with its high level of engagement with the natural, and/or cultural/social host environments provides an opportunity to crease a sense of place and a learning environment that fosters transformative learning.

By way of illustration, the importance of place is evident in the marketing of volunteer tourism projects. The Lonely Planet has recently published a guide to volunteering overseas and the Green Volunteer guide is now in its fifth edition, printed in 2005, also listing 200 volunteer tourism organisations, primarily in Central and South America (see Ellis, 2003; Callanan \& Thomas, 2005; Cousins, 2007 for a review of VT locations and project types). From the above studies, there would appear to be a clear trend towards projects that market exotic tourist destinations, colourful cultures and charismatic animals. 
Returning to O'Sullivan's notion of an education for community and a sense place, we find many opportunities to explore new communities in volunteer tourism. Projects with a social and cultural development, religious/pilgrimage and school- or familybased projects are listed in the Green Volunteers' two sister publications, World Volunteers, listing humanitarian and development volunteering, and Archaeovolunteers, which lists archaeological and heritage volunteering opportunities, and by academic studies of social and cultural development projects (c.f. Brown \& Letho, 2005; Brown \& Morrison, 2003, Lyons, 2003; McGehee \& Andereck, 2009; McGehee \& Santos, 2-5; Mclntosh \& Zahara, 2007; Mustonen, 2005; Stoddart and Rogerson, 2004). A number of these studies highlight the importance of cultural exchange. For instance, Mclntosh and Zahra (2007, p.553) capture the local community's views in their study of volunteer tourists in a Maori community. They conclude that volunteer tourism enables a new narrative to be created between host and volunteer tourist, one that is engaging, genuine, creative and mutually beneficial, and has the potential to foster creative, alternative and more sustainable forms of tourism activity.

\section{Disorienting dilemmas: evidence of challenging experiences and emotions} The role of emotions in transformative learning is widely accepted (c.f. Cranton \& Roy, 2003; Illeris, 2003; Yorks \& Kasl, 2006; Taylor, 2007). We have already touched upon O'Sullivan's espousal of a grieving period in transformative learning. Taylor (2007) refers to the affective tone of students who are interviewed about their transformative learning experience; the student's affective tone varied widely from frightening and unpleasant feelings to feelings of joy and excitement. Taylor points out that the students will need support as they work through the discomfort of what Mezirow calls "disorienting dilemmas".

Disorienting dilemmas have been described as internal or external personal crises (Mezirow 1978) or integrating circumstances in which individuals search for something that is missing from their lives. This can have many different effects on learners depending on their personality, experience, age, status in the program, personal issues that they are coping with at the time, the nature of the disorienting dilemma and the approach adopted by adult educator (Roberts, 2006). Cranton (1994, p.72) suggests that transformative learning may be experienced as "a prolonged period of confusion and muddling that is followed by a breakthrough or sense of enlightenment". Volunteer tourism experiences elicit strong emotional responses from tourists, which can be captured through studies of volunteer tourists' 
journals. Coghlan (2005) used this method to study volunteer tourists' onsite experiences.

An example of some of the volunteer tourists' diary entries illustrates the role of experiencing new and different things, as well as personal development in volunteer tourism:

"by far this was one of the best days of my life. [...] climbing to the crow's nest was hands-down the best experience of the day. It was at the same time the most exhilarating experience of my life. My fear of heights has kept me from doing a lot, but I was determined to do this. It was all worth it, the view was breathtaking and the feeling was indescribable".

In a similar study, trends of fluctuating satisfaction and emotion types are noted throughout the week (Coghlan \& Pearce, 2010). Periods of negative emotions, such frustration, irritation, discontent, worry and tenseness, were often experienced towards the middle of the projects. An example of the progression of emotions is provided by a North American volunteer. She commented on her feeling of inadequacy, saying that "you bring all your existing hang-ups with you". A few days later, she reports that "it is sobering to realise how much you take for granted".

This respondent's last comment picks up on a common theme for authors both within the field of volunteer tourism and transformative learning; the re-appraisal of personal values, lifestyle choices, and issues around development. Broad (2003) reports a changed way of looking at the world in volunteers working in Thailand, Halpenny and Caissie (2003) describe how volunteer tourists reflect upon their own behaviour and values, Zahra and McIntosh (2007) cite the cathartic nature of volunteer tourism that permits individuals to re-orients one's life and values, Crabtree (1998) reports how volunteer tourism brings about education in citizenship and empowerment, whilst Unstead-Joss (2008) suggests that volunteer tourism presents opportunities to redress power imbalances and engage in the "conscientiasation" of development .

Both of these themes, re-appraising personal values and redressing power imbalances, may be related to the issues of individuation, authenticity and emancipatory learning discussed in the literature on transformative learning. The latter include those approaches that emphasise the importance of praxis and social change as an outcome of transformative learning (c.f. van Gorder, 2007, for a 
discussion of this as it relates to the volunteer tourism context). Individuation and authenticity refer to the way in which we gradually become conscious of our own unique psychological makeup over our lifetime" (p.91), (i.e. self-actualisation in volunteer tourism terms), and how we express this new, genuine self in the community, an implicit or desired outcome of volunteer tourism.

O'Sullivan (1999) challenges us to remove ourselves from the Eurocentric view of development, by adopting an alternative, people-centred paradigm; it is a development "enacted by the people concerned, based on their knowledge, experience and culture", and by "the mobilisation of local resources to meet perceived local needs" (p.112). Whilst challenging the development paradigm is an important feature of volunteer tourism, it is not uncontested (c.f. Moore McBride, Brav, Menon \& Sherraden, 2006; Raymond \& Hall, 2008). In her paper entitled "Doing development" Simpson (2004) affirms that many volunteer tourist projects lack critical engagement between the participants and their surroundings, neglecting to challenge the assumptions of the tourists, instead re-affirming their initial assumptions, and allowing them to focus on their own fortunes, lifestyles, and values. This is supported by studies such as Gray and Campbell's (2007) study of volunteer tourists in Costa Rica; these authors suggest that we may inappropriately propagate western values through volunteer tourism. Finally, Leigh (2006) presents the case of "reverse cultural shock" as volunteer tourists re-enter their home culture, and may not be able to reconcile their skills, values and attitudes they developed during their volunteer tourism experience.

\section{Importance of dialogue and reflection: volunteer tourism as a personal journey in a group setting}

As noted in the introduction to Mezirow's phases of transformative learning, there is a strong element of sharing the experience with others (phase 4), which Mezirow emphasizes in a later paper entitled Transformative learning as discourse. Building on later work, Taylor (1987) identifies an exploration stage that follows the disorienting dilemma or disconfirmation stage. Cranton (1994) described this exploration stage as a "collaborative, open-ended activity that produces insight and confidence" (p.71). This is followed by a transition phase, called sharing the discovery, where the learner tests the new understanding with others. Clearly the group environment with other volunteers on the same journey may provide a good setting for discussion and self-reflection. 
Many scholars of transformative learning highlight the importance of providing a safe, inclusive and open learning environment (Taylor, 2006). He states that the learning process is dependent on the need for support, trust, friendship and intimacy. These represent some of the conditions needed for learner empowerment, where the learner feels confident, secure, free, equal, assisted by a sensitive facilitator and supported by others. Brookfield (1987, p.29) asserts that the support of others "assist us in breaking out of our own frameworks of interpretation. We hold up our behaviour for scrutiny by others and in their interpretation by others we are given a reflection, a mirroring of our actions of our own actions from an unfamiliar psychological vantage point". Other participants also play a role in questioning and challenging a learner. This is an integral part of the critical learning process.

Another significant aspect transformative learning is providing the opportunity to create a new personal narrative. O'Sullivan suggests deconstructing our existing paradigms, in order to create reflective space for this new narrative. McIntosh and Zahra (2007) found that volunteer tourism enables a new narrative to be created between host and volunteer tourist, one that is engaging, genuine, creative and mutually beneficial, and has the potential to foster creative, alternative and more sustainable forms of tourism activity.

The creation of a narrative may also take place in a more private setting. Simpson (2005) makes a strong plea for greater critical reflection in volunteer tourism, and a structured, pedagogic approach to creating reflective practices. Raymond and Hall (2008) indicate ways to facilitate this learning through reflection in their participants by keeping journals, or by requiring assignments such as essays, applications, and evaluations. This is in line with Taylor (2007) who suggests the use of writing, particularly journaling and thesis writing, as a medium to promote transformative learning.

\section{Self-actualisation as an outcome of transformational learning}

The notion of participants' self-actualisation has been a driving force in the academic study of volunteer tourism. It appears in some of the seminal literature in the field; in one of the earliest studies of volunteer tourism, Wearing and Neil (2001) noted that throughout the literature on international travel and volunteering there is a strong focus on personal development and the role of learning in changing or influencing the 
self. This learning element, which is central to many volunteer tourism expectations and experiences, may take the form of academic knowledge, the development of personal knowledge, self-confidence, independence, cultural awareness and social abilities (Wearing, 2004; Webb, 2002).

In a similar vein, past research has identified the benefits that participants derived from their experience (Broad, 2003; Brown \& Letho, 2005; McGehee \& Santos, 2005; McIntosh \& Zahra, 2007; Simpson, 2004; Wearing, 2003). These focus on three areas; (i) personal development and self-fulfilment, particularly a great sense of empowerment and independence, increasing self-awareness and a spiritual development by reflecting on Western values, (ii) knowledge gain and increased skills, and finally (iii) enhanced interpersonal relations and social networks.

Returning the theme of empowerment raised by Cranton (1999), volunteer tourism is also said to build social capital by bringing about a social justice awareness in participants through emancipatory learning. According to social capital theory, people through their social networks, develop shared norms, trust and reciprocity, and these social interactions and relationships have value (Putnam, 1993; Bourdieu, 1986). When some VT participants return to their home country, they bring with them a new awarenss of the power generated through social capital. An example of this is provided by Wearing citing Hill (2001, p.28); he says that participants come home feeling that "you don't have limits. You feel a lot more confident in your ideas, and beliefs and you can contribute to society". This theme of contributing to society has been followed by McGehee (2001) and McGehee and Santos (2005) in their studies of social networks and engagement as an aftermath of volunteer tourism. Their results suggest that participation in volunteer tourism has on-going positive effects, particularly in encouraging support for activism and intentions to engage in post-trip social movement activities.

Whilst critical perspectives on the nature of volunteer tourism are becoming more prevalent in the literature (Gray \& Cambell, 2007; Guttentag, 2009; Raymond \& Hall, 2008; Simpson, 2005; Unstead-Joss, 2008; Lyons \& Wearing, 2008a, b), the topic of volunteer tourist self-actualisation remains significant in many studies (as illustrated above). It would appear to be a reflection of three of Mezirow's latter five phases of transforming learning, exploring options for new ways of acting, building competence and new ways of acting, acquiring knowledge and skills for implementing one's plans. The inclusion of the remaining two steps "developing a plan of action" and 
"provisional efforts to try out new roles and gain feedback" provide the framework to move volunteer tourism beyond a simple rhetoric of "doing something worthwhile" to life changing experiences that benefit the volunteer, the host community, the environment and society at large.

\section{Concluding comments and future research}

In conclusion, this paper recognizes many of the challenges faced by volunteer tourism to meet the expectations of academics, practitioners, host communities and tourists alike. As a sector yet in its infancy, it may need time to develop its identity along with the tools and strategies that will serve its cause most effectively. This paper reviews one body of literature, drawn from social learning and education that may facilitate some of the changes advocated by researchers in this field.

We have highlighted some of the ways that the context of volunteer tourism marry up with the theory of transformative learning, in order to promote critical thinking around the practice of volunteer tourism. We suggest a need to design opportunities for volunteer tourists to develop their plan of action, and to apply provisional efforts to try out their new roles and gain feedback on their efforts. Furthermore, whilst there has been a strong emphasis on encouraging the "individuation" process as described by Cranton and Roy (2003), we see less evidence of the development of authenticity that may encourage emancipatory learning.

We also recognize that the ideas presented here are but a first attempt at reconceptualising volunteer tourism. We hope to point to a rich source of inspiration and knowledge that may enhance the social and individual outcomes of volunteer tourism. Other areas that merit further investigation are the some of the factors that prevent volunteer tourism from accomplishing societal transformation and how to foster transformative learning within volunteer tourism organisations, as well as adopting a community-based perspective on volunteer tourism, to understand the role hosts may play in forging a path of transformative learning and finally to address some of the issues around authenticity and emancipatory learning as volunteer tourism plays its part in redressing growing social and environmental issues. These themes will form the focus of future papers adapting transformative learning theory to the practice of volunteer tourism. 


\section{References:}

Acott, T, La Trobe, H, Howard, S. 1998. An evaluation of Deep ecotourism and Shallow ecotourism. Journal of Sustainable Tourism 6: 238-253

Basinger, J. (1998). To the Scientists Who Use Paying Volunteers in Fieldwork, the Benefits Outweigh the Bother. The Chronicle of Higher Education 44(41): A14-A15.

Bourdieu, P. (1986) The forms of capital, in: J. Richardson (Ed.) Handbook of Theory and Research for the Sociology of Education New York, Greenwood. pp. 241-248.

Broad, S. (2003). Living the Thai life - a case study of volunteer tourism at the Gibbon Rehabilitation Project, Thailand. Tourism Recreation Research 28(3): 63 - 72

Brookfield, S. (1987). Developing Critical Thinkers: challenging adults to explore alternative ways of thinking and acting. San Francisco: Jossey-Bass.

Brookfield, S. (2000). Transformative Learning as Ideology Critique. In J. Mezirow et al. (Eds.) Learning as Transformation; Critical Perspectives on a theory in Progress (pp. 125 - 148). San Francisco: Jossey-Bass

Brown, A. and Morrison, A. (2003). Expanding Volunteer Vacation Participation: an exploratory study on the mini-mission concept. Tourism Recreation Research 28(3): 73-82.

Brown, S. and Lehto, X. Y. (2005). Traveling with a purpose: Understanding the motives and benefits of volunteer vacationers. Current Issues of Tourism, 8(6), 479-496.

Butler, R. (1990). Alternative tourism: pious hope or Trojan horse? Journal of Travel Research 28(3): 40-45.

Canfield, D. (1994). Putting Data to Use. The Volunteer Monitor 6(1).

Coghlan, A. (2005). Towards an Understanding of the Volunteer Tourism Experience. Unpublished PhD thesis, James Cook University, Townsville. 
Coghlan, A. and Pearce, P. (2010) Tracking affective components of satisfaction. Tourism and Hospitality Research, 10 (1). pp. 1-17.

Crabtree, R. (1998). Mutual Empowerment in cross-cultural participatory development and service learning: lessons in communication and social justice from projects in El Salvador and Nicaragua. Journal of Applied Communication Research, 26(2): 182-209.

Cranton, P. (1994). Understanding and promoting transformative learning: a guide for educators of adults. Jossey-Bass, San Francisco.

Cranton, P. and Roy, M. (2003). When the Bottom Falls Out of the Bucket. Journal of Transformative Education 1(2): 86-98.

Cousins, J.A., Evans, J, \& Sadler, J. (2009). Selling conservation? Scientific Legitimacy and the commodification of conservation tourism. Ecology and society 14(1): $32-49$.

Donald, B. (1997) Fostering volunteerism in an environmental stewardship group: a report on the task force to bring back the Don, Toronto, Canada. Journal of Environmental Planning \& Management, 40(4), pp.483-505.

Ellis, C. (2003). Participatory Environmental Research in Tourism: a global view. Tourism Recreation Research 28(3): 45-55.

Evans, S. M. and Birchenough, A.C. (2001). Community-based management of the environment: lessons from the past and options for the future. Aquatic Conservation: Marine And Freshwater Ecosystems 11: 137-147.

Foster-Smith, J. and Evans, S. M. (2003). The Value of Marine Ecological Data Collected by Volunteers. Biological Conservation 113: 199-213.

Gazley, B. (2001). Volunteer Vacations and What Research Can Tell Us About Them.E-Volunteerism, 1(2). http://e-volunteerism .com/win2001/vacintro.html (accessed Jan 2008). 
Gowing, G. and Major, R. E. (1995). The 'Nest Test' Experiment: are community involvement and good science mutually exclusive. Museum Management and Curatorship 14(2): 169-180.

Gray N.J. and Campbell, L.M. (2007) A decommodified experience? Exploring aesthetic, economic, and ethical values for volunteer ecotourism in Costa Rica. Journal of Sustainable Tourism 15(5) 463-482 .

Guttentag, D. (2009). The possible negative impacts of volunteer tourism. International Journal of Tourism Research 11: 537-551.

Hartman, J. (1997). The popularisation of science. Public Understanding of Science 6: 69-86.

Illeris, K. (2003). Towards a contemporary and comprehensive theory of learning International Journal of Lifelong Education, 22(4): 396-406.

Leigh, D. (2006) .Third cultured volunteer tourists and the process of re-assimilation into home environments. Australian Journal on Volunteering 11(2): 59-67.

Lindberg, K, Enriquez, J, Sproule, K. 1996. Ecotourism Questioned: case studies from Belize. Annals of Tourism Research 23: 543-562.

Lyons, K. \& Wearing, S. (2008a) Journeys of Discovery in Volunteer Tourism. CABI International: Wallingford.

Lyons, K. \& Wearing, S. (2008b). Volunteer tourism as Alternative Tourism: Journeys beyond otherness. In Lyons, K. \& Wearing, S. (2008) Journeys of Discovery in Volunteer Tourism. CABI International: Wallingford.

McGehee, N. (2002). Alternative tourism and social movements. Annals of Tourism Research 29(1): 124-143.

McGehee, N. and Andereck, K. (2009). Volunteer tourism and the "voluntoured": the case of Tijuana, Mexico. Journal of Sustainable Tourism 17(1): 39-51. 
McGehee, N. and Andereck, K. (2008) Pettin' the Critters': Exploring the complex relationship between volunteers and the voluntoured in McDowell County, WV, USA and Tijuana, Mexico" in S. Wearing and K. Lyons (eds) Journeys of Discovery in Volunteer Tourism: International Case Study Perspectives. CABI, Oxfordshire, UK.

McGehee, N. and Santos, C. (2005). Social Change, Discourse and Volunteer Tourism. Annals of Tourism Research 32(3): 770-779.

McIntosh, A. and Zahra, A. (2007). A Cultural Encounter through Volunteer Tourism: towards the ideals of sustainable tourism. Journal of Sustainable Tourism 15(5): 541 556.

Mezirow, J. (1975). Education for perspective transformation: women's re-entry programs in community colleges. Centre for Adult Education, Teachers College, Columbia University: New York.

Mezirow, J. (1978). Perspective Transformation. Adult Education 28:100-110.

Mezirow, J. (1991). Transformative dimensions of adult learning. San Francisco: Jossey-Bass.

Mezirow, J. (2000). Learning to think like an adult: core concepts of transformative theory. In J. Mezirow, and Associates (eds.), Learning as transformation: critical perspective on a theory in progress. San Francisco: Jossey-Bass, pp. 3-33.

Mezirow, J. (2003). Transformative Learning as Discourse. Journal of Transformative Education 1(1): 58-63.

Moore McBride, A., Brav, J., Menon, N. and Sherraden, M. (2006). Limitations of civic service: critical perspectives. Community Development Journal 41(3): 307-320.

Mumby, P. J., A. R. Harbourne, et al. (1995). A critical assessment of data derived from Coral Cay Conservation volunteers. Bulletin of Marine Science 56(3): 742-756.

Napier, R.W., \& Gershenfeld, M.K. (1999) Groups: theory and practice. Sixth edition. Houghton Mifflin Company Boston, NY 
Newman, C., Bueschin, C. D. et al. (2003). Validating Mammal Monitoring Methods and Assessing the Performance of Volunteers in Wildlife Conservation: "sed quis custodiet ipsos custodies?" Biological Conservation 113: 189-197.

O'Sullivan, E. (1999). Transformative Learning: Education vision for the $21^{\text {st }}$ Century. Zed Books; London.

O'Sullivan, E. (2002). The Project and Vision of Transformative Education: Integral Transformative Learning. In E. O'Sullivan, A, Morrell, M.A. O'Connor (Eds.) Expanding the Boundaries of Transformative Learning: Essays on theory and praxis. New York: Palgrave.

Page, S. and Dowling (2002). Ecotourism. London, Prentice-Hall-Pearson Education Ltd.

Pearce, J.L. (1993) Volunteers: the organisational behaviour of unpaid workers Routledge, London, UK.

Percy, R. (2005). The contribution of transformative learning theory to the practice of participatory research and extension: theoretical reflections. Agriculture and Human Values 22: 127-136.

Putnam, R. D. (1993) Making Democracy Work: civic traditions in modern Italy Princeton, NJ, Princeton University Press.

Raymond, E.M. and Hall, C.M. (2008). The Development of Cross-Cultural (Mis)Understanding through Volunteer Tourism. Journal of Sustainable Tourism 16(5): 530-543.

Roberts, N. (2006). Disorienting dilemmas: Their effects on learners, impact on performance, and implications for adult educators. In M. S. Plakhotnik \& S. M. Nielsen (Eds.), Proceedings of the Fifth Annual College of Education Research Conference: Urban and International Education Section (pp. 100-105). Miami: Florida International University. http://coeweb.fiu.edu/research conference/.

Simpson, K. (2004). "Doing Development": the gap year, volunteer tourists and a popular practice of development. Journal of International Development 16: 681-692. 
Simpson, K. (2005). Dropping out or Signing up? The Professionalism of Youth Travel. Antipode 37:447-467.

Stebbins R 1996, 'Volunteering: A serious leisure perspective', Nonprofit and Voluntary Sector Quarterly 25 (2.June), pp. 211-24

Stebbins R 2001, 'Serious leisure', Sociely, vol. 38, no. 4, pp. 53-7

Stebbins, R.A. and Graham, R.T. (2004). Volunteering as Leisure/Leisure as Volunteering.Wallingford, Ox., UK.

Sipos, Y., Battisti, B., and Grimm, K. (2008). Achieving transformative sustainability learning: engaging head, hands and heart. International Journal of Sustainability in Higher Education 9(1): 68-86.

Taylor, E. (1998). Transformative learning: a critical review. ERIC Clearinghouse on Adult, Career and Vocational Education (Information Series No. 374).

Taylor, E. (2007). An update of transformative learning theory: a critical review of the empirical research (1999-2005). International Journal of Lifelong Education 26(2): 173-191.

United Nations General Assembly 2001. Support for Volunteering: Report of the Secretary-General, United Nations, New York.

Unstead-Joss, R. (2008). An Analysis of Volunteer Motivation: implications for international development. Journal of the Institute for Volunteering Research 9(1): 320.

Van Gorder, A. (2007). Pedagogy for the Children of the Oppressors: Liberative Education for Social Justice among the World's Privileged. Journal of Transformative Education 5(1): 8-32.

Wearing, S. (2001). Volunteer Tourism: experiences that make a difference. New York, Cabi Publication. 
Wearing, S. (2002). Recentering the self in volunteer tourism. In Dann, G. (ed.) The Tourist as a Metaphor of the Social World. CAB international: London.

Wearing, S. (2003). Re-Centering the Self in Volunteer Tourism. The Tourist as a Metaphor of the Social World. G. M. S. Dann. (ed.) CABI: Oxford.

Wearing, S. (2004). Examining Best Practice in Volunteer Tourism. Volunteering as Leisure/Leisure as Volunteering. R. A. Stebbins and R. T. Graham. (eds) Wallingford, Ox., UK.

Wearing, S. and J. Neil (1997). Tourism that Counts: ecotourism, volunteerism and serious leisure. Australian Tourism and Hospitality Research Conference, Canberra.

Weaver, D. 2001. Ecotourism as Mass Tourism: Contradiction or Reality? Cornell Hotel and Restaurant Administration Quarterly 42: 104-112.

Webb, D. (2002). "Investigating the Structure of Visitor Experiences in the Little Sandy Desert, Western Australia." Journal of Ecotourism 1(2\&3): 149-161.

Weiler, B. and Davis, D. (1993). An exploratory investigation into the roles of the nature-based tour leader. Tourism Management 14(2): 91-98.

Weiler, B. and Richins, H. (1995). Extreme, Extravagant and Elite: a profile of ecotourists on Earthwatch expeditions. Tourism Recreation Research 20(1): 29-36.

Wenger, E. (1998) Communities of practice: Learning, meaning, and identity Cambridge University Press; Cambridge.

West, P. (2008). Tourism as Science and Science as Tourism. Current Anthropology 49(4): 597-626.

Yorks, L. and Kasl, E. (2006). I know more than I can say: a taxonomy for using expressive ways of knowing to foster transformative learning. Journal of Transformative Learning 4(1): 43-64.

Zahra, A. and Mclntosh, A. (2007). Volunteer tourism: Evidence of Cathartic tourist experiences. Tourism Recreation Research 32(1): 115-119. 